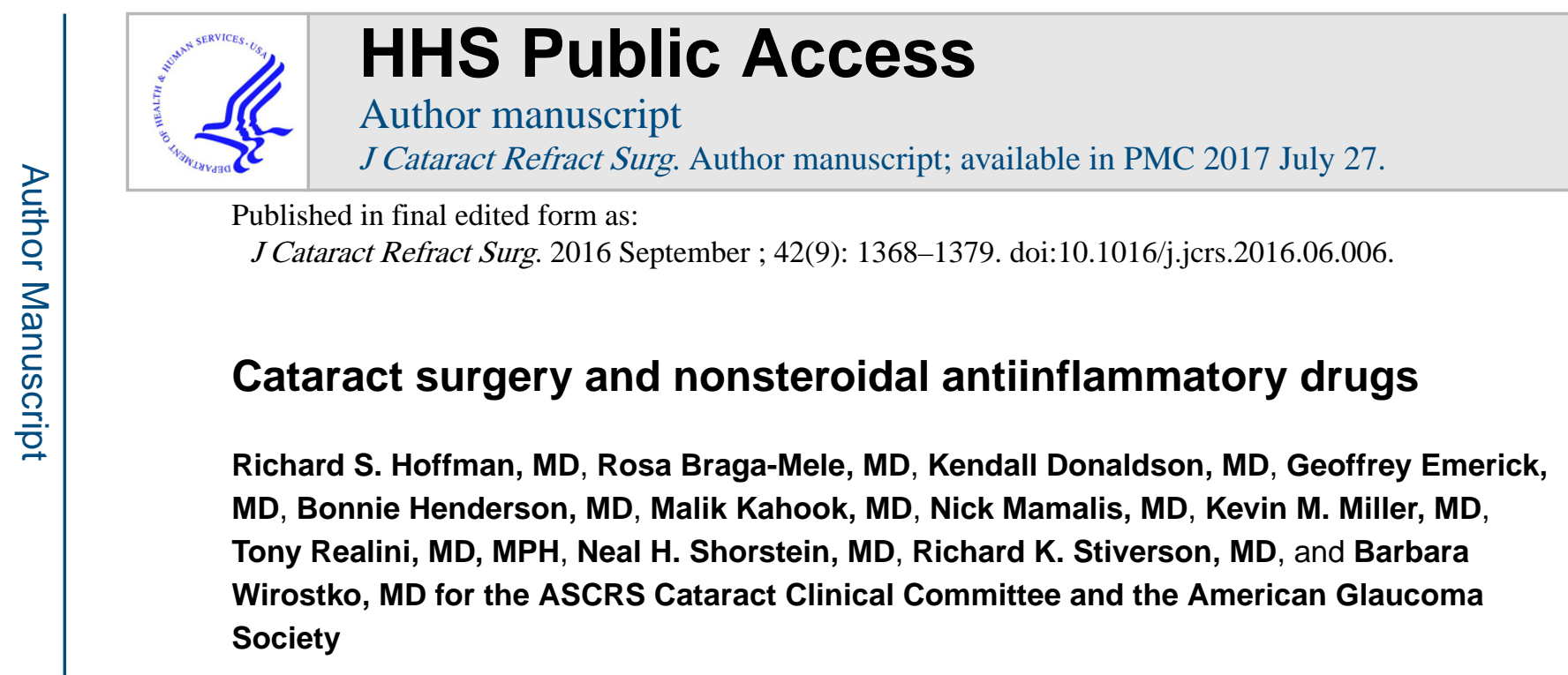

\title{
Abstract
}

Nonsteroidal antiinflammatory drugs (NSAIDs) have become an important adjunctive tool for surgeons performing routine and complicated cataract surgery. These medications have been found to reduce pain, prevent intraoperative miosis, modulate postoperative inflammation, and reduce the incidence of cystoid macular edema (CME). Whether used alone, synergistically with steroids, or for specific high-risk eyes prone to the development of CME, the effectiveness of these medications is compelling. This review describes the potential preoperative, intraoperative, and postoperative uses of NSAIDs, including the potency, indications and treatment paradigms and adverse effects and contraindications. A thorough understanding of these issues will help surgeons maximize the therapeutic benefits of these agents and improve surgical outcomes.

\begin{abstract}
Modern cataract and lens surgery is commonly facilitated by the use of topical medications before and after the surgical procedure. These topical medications may include antibiotics, steroids, nonsteroidal antiinflammatory drugs (NSAIDs), and the full array of glaucoma medications to modulate intraocular pressure (IOP) in the perioperative period. Many surgeons have found NSAIDs to be an indispensable tool for providing the best surgical outcomes in both routine and complicated cataract procedures. As a class of drugs, NSAIDs have been proven to be a safe and effective alternative to corticosteroids in the topical prevention and management of noninfectious ocular inflammation and cystoid macular edema (CME). ${ }^{1,2}$ They have also been valued as a means of maintaining intraoperative mydriasis and moderating postoperative pain. Whether used alone, synergistically with corticosteroids, or for specific high-risk eyes prone to the development of CME, the effectiveness of these medications is compelling.
\end{abstract}

This paper reviews the literature on currently available topical and intracameral NSAIDs and their various uses in cataract and lens surgery, with specific attention to the prevention and

Corresponding author: Richard S. Hoffman, MD, Drs. Fine, Hoffman Sims, LLC, 1550 Oak Street, Suite 5, Eugene, Oregon 97401, USA. rshoffman@finemd.com.

Financial Disclosure: Drs. Braga-Mele, Donaldson, Henderson, and Kahook are consultants to Allergan, Inc. Drs. Braga-Mele, Donaldson, Henderson, Kahook, Miller, and Realini are consultants to Alcon Laboratories, Inc. Drs. Henderson and Pasquale are consultants to Bausch \& Lomb. Dr. Miller is a consultant to Abbott Medical Optics, Inc. Dr. Pasquale is a consultant to Novartis and has been a speaker for Allergan, Inc. None of the other authors has a financial or proprietary interest in any material or method mentioned.

Shan Lin, MD, and Louis R. Pasquale, MD, reviewed the final paper. 
treatment of pseudophakic CME and to the assorted treatment paradigms for addressing both routine and high-risk cases. In addition, special consideration of patients with coexistent glaucoma having cataract surgery will focus on the potential effectiveness and benefits of using NSAIDs in these patients. Possible adverse reactions and contraindications will also be reviewed.

\section{Mechanism of Action}

Commercially available NSAIDs consist of a chemically heterogeneous group of compounds that can be grouped into 6 major classes: salicylates, fenamates, indoles, phenylalkanoic acids, phenyl acetic acids, and pyrazolones. ${ }^{2,3}$ Despite their chemical heterogeneity, all NSAIDs act by blocking the cyclooxygenase (COX) enzymes, COX-1 and COX-2, thereby reducing or blocking the production of prostaglandins. The COX-2 enzyme is more prevalent in the inflammatory response than COX-1,, 4 and thus the potency of inhibition of COX-2 tends to determine the clinical efficacy of the NSAID.

\section{Mode of Delivery}

Nonsteroidal antiinflammatory drugs can be administered systemically, topically, or, more recently, intracamerally. Topically applied NSAIDs are commonly used to manage ocular inflammation, and many forms are available. Local side effects due to topical instillation may occur, but ocular penetration of most commercially available topical NSAIDs seems to be adequate for both anterior and posterior segment inflammation. ${ }^{1,3,4}$ The ocular penetration and efficacy of systemic NSAIDs is questionable compared with those of topical treatment, and given the larger potential systemic side effects associated with oral NSAIDs, it is unlikely that systemic NSAIDs will play a significant role in the treatment of intraocular inflammation. A recent formulation for intracameral use during cataract surgery to potentially assist with mydriasis and reduce pain during surgery is available.

\section{Currently Available Topical Ophthalmic Nonsteroidal Antiinflammatory Drugs}

The currently available topical ophthalmic NSAIDs including generic and brand drug names, manufacturer, dosage, bottle size, and indications are listed in Table 1.

\section{Penetration and Efficacy of Topical Ophthalmic Nonsteroidal Antiinflammatory Drugs}

Due to the physiologic barrier of the ocular surface and the composition of the aqueous, many NSAID molecules must be altered to enhance their availability. These agents are primarily weakly acidic drugs that ionize at the $\mathrm{pH}$ of the tear film, therefore limiting corneal permeability since the cornea has an isoelectric point of 3.2. ${ }^{4}$ To increase permeability, the $\mathrm{pH}$ must generally be raised, thereby increasing the unionized fraction of the drug. Since the formulation is acidic, this increases the irritant potential while improving corneal penetration and decreasing aqueous solubility. ${ }^{5}$ Preservatives such as benzalkonium chloride (BAK) have been added to the formulations to increase penetration; however, these preservatives also increase ocular surface irritation. 6,7 
Bromfenac-The bromfenac molecule has been altered to make it more lipophilic to improve corneal penetration, increase duration of action, and enhance COX-2 inhibition. ${ }^{8}$ It has good ocular penetration with insignificant systemic reactions following topical administration. Bromfenac has been found to be 3.7, 6.5, and 18.0 times more potent as a COX-2 inhibitor than diclofenac, amfenac, and ketorolac, respectively. ${ }^{9-11}$ It has been found to be a very potent inhibitor of prostaglandin production. ${ }^{12}$

Diclofenac-In its usual phenyl acetic acid form, diclofenac has poor aqueous solubility; thus, it is typically used in the sodium salt form to increase its solubility. ${ }^{13}$ Additionally, at the physiologic $\mathrm{pH}$ of the eye, diclofenac has limited permeability and must be buffered to a lower $\mathrm{pH}(6.0)$ to increase corneal penetration. ${ }^{7}$ However, decreasing the $\mathrm{pH}$ of the solution results in precipitation, and thus stabilizers must be used. ${ }^{14}$ To improve the poor aqueous solubility and corneal penetration, an oily formulation (in sesame oil) was created.

Flurbiprofen-The flurbiprofen molecule is an inhibitor of prostaglandin synthesis that is essentially insoluble in water. Penetration of flurbiprofen was found to be highest at a $\mathrm{pH}$ of 6.4 and decreased as the $\mathrm{pH}$ was increased into the physiologic range. ${ }^{6}$ Corneal penetration also increased with the presence of BAK due to an increase in lipid solubility and through the addition of phenyl mercuric nitrate. Adding cyclodextrin has also increased corneal permeability. Reducing the $\mathrm{pH}$ of the cyclodextrin-containing formulation has further improved permeability. ${ }^{15}$

Ketorolac-Ketorolac is commercially available as a tromethamine salt, which has better aqueous solubility than the native ketorolac molecule. The molecule is extremely irritating to the ocular surface; thus, lower concentrations $(0.4 \%)$ have been advocated to reduce this bothersome side effect. Reducing the $\mathrm{pH}$ of the molecule increases corneal permeation, so the formulation is prepared in a phosphate buffer that reduces the $\mathrm{pH}$ to 4.5 . Because ketorolac is a very unstable molecule that has improved stability at higher $\mathrm{pH}$ (6.5 to 8.5), there is a fine balance between efficacy and penetration of the medication. ${ }^{16}$ Preservation of the molecule with BAK (or similar preservatives except thimerosal) also increases corneal penetration but may be associated with increased ocular surface irritation. Preparing ketorolac with a combination of BAK and ethylenediaminetetraacetic acid $0.01 \%$ provided the best corneal penetration relative to other available preservatives. ${ }^{17}$ Ketorolac is the only topical NSAID available in a preservative-free formulation (Acuvail, $0.45 \%$ ), which is more gentle on the ocular surface and may be better tolerated in patients sensitive to preservatives such as BAK.

Nepafenac-Nepafenac is a prodrug that rapidly penetrates the cornea. In comparisons of nepafenac and diclofenac, nepafenac penetrated the cornea 6 times faster in vitro. ${ }^{18}$ Once the molecule enters the aqueous, it is deaminated by intraocular hydrolases to amfenac, a potent COX-1 and COX-2 inhibitor. ${ }^{19}$ Studies have shown that nepafenac may be more potent than ketorolac or diclofenac. ${ }^{20}$ The prodrug nature of the molecule has been debated, and there are mixed opinions about the true benefits of administering the drug in this form. 


\section{Intracameral Ketoralac-Phenylephrine}

A recently approved combination of phenylephrine $1.0 \%$ and ketorolac $0.3 \%$ injectable solution, Omidria, was designed to prevent intraoperative miosis and reduce intraoperative pain. It is added to the irrigating solution used during cataract surgery and is thus delivered throughout the surgical procedure. Since ketorolac inhibits both COX enzymes (COX 1 and COX 2), it is able to dramatically reduce prostaglandin synthesis that occurs in the anterior chamber due to surgical trauma. Phenylephrine is an a-adrenergic agent that promotes pupillary mydriasis through contraction of the radial muscle of the iris. In combination, phenylephrine and ketorolac function through 2 different mechanisms to promote pupillary dilation during cataract surgery.

\section{Ophthalmic Uses for Nonsteroidal Antiinflammatory Drugs}

Nonsteroidal antiinflammatory drugs block the conversion of arachidonic acid by COX-1 and COX-2 into prostaglandin intermediates and subsequently into a variety of eicosanoids including prostacyclin, thromboxane, and prostaglandins. ${ }^{21,22}$ Of these, prostaglandins play a key role in the manifestation of ocular inflammation. They contribute to leukocyte recruitment and migration, and through their effects on the vasculature (dilation and permeability) may contribute to protein in the aqueous humor, erythema, and hyperemia. ${ }^{23}$

Prostaglandins are also implicated in causing smooth-muscle contraction in the iris. In addition to blocking the inflammatory cascade to prevent inflammation and pain postoperatively, NSAIDs play a role in preventing miosis during surgery. ${ }^{24}$ This has been widely accepted as an important role of NSAIDs to improve visualization during cataract surgery as poor iris dilation has been associated with an increased risk for complications. ${ }^{25}$

Another and arguably the most important use of NSAIDs in cataract surgery is for prevention of CME. Although the incidence of pseudophakic CME is relatively low, it is problematic when it occurs and raises concern in patients who develop it. Most surgeons use topical steroids with or without topical NSAIDs as their postoperative medication regimen. However, some studies have shown that topical NSAIDs are more effective in preventing CME than steroids alone. Nonsteroidal antiinflammatory drugs have been found to be well tolerated with few side effects in appropriate patients and are therefore recommended to prevent CME, especially for high-risk patients..$^{26,27}$

A less known use of NSAIDs is for prevention of lens epithelial cell (LEC) proliferation. Nishi et al. ${ }^{28}$ first reported the suppressive effect of diclofenac sodium on LEC metaplasia and proliferation in 1991. When diclofenac sodium was added to cultured human LECs, the authors found cell degeneration and death on histopathologic examination. They hypothesized that NSAIDs use might deter posterior capsule opacification (PCO) by preventing the anterior LECs from multiplying and migrating.

\section{Nonsteroidal Antiinflammatory Drugs and Cystoid Macular Edema}

Pseudophakic CME is a complication of cataract surgery that occurs secondary to accumulation of fluid in the macula and causes swelling with subsequent decreased vision. 
The incidence of pseudophakic CME varies and depends on how CME is defined. Earlier studies using fluorescein angiography have found that CME is not uncommon following cataract surgery but is often noted without loss of visual acuity. When loss of visual acuity is used to define the diagnosis of CME, the incidence drops considerably. The incidence of visually significant $\mathrm{CME}$ varies from $0.1 \%$ to $3.5 \%$ in general studies that included eyes with comorbidities, such as diabetes mellitus and epiretinal membranes, and in studies that included large-incision extracapsular surgeries. ${ }^{29-37}$ These are large national studies that would be expected to have similar rates of ocular comorbidity. When studies that include significant numbers of large-incision surgeries are removed, leaving cases performed $95 \%$ or more of the time by phacoemulsification, the incidence of visually significant CME drops to $2 \%$ or less. ${ }^{32-36}$ In 1 study, ${ }^{36}$ the incidence of CME detectable by optical coherence tomography (OCT) was $0.1 \%$ following phacoemulsification.

Cystoid macular edema is thought to be caused by the release of inflammatory mediators such as prostaglandins during cataract surgery, which can lead to an increase in vascular permeability with subsequent edema in the macula. This condition has been noted more frequently in patients with any type of increased postoperative inflammation or a complicated cataract surgery that can lead to increased inflammation. Due to the relationship between prostaglandin release and CME, using topical corticosteroids and topical NSAIDs to reduce postoperative inflammation following cataract surgery may prevent CME.

\section{Preoperative Use for Prevention of Cystoid Macular Edema}

Although numerous studies have examined the incidence of postoperative CME following cataract surgery in which topical NSAIDs were started the day before surgery and continued through the postoperative study period, only 2 reports have examined whether preoperative prophylaxis decreases the likelihood of developing postoperative CME. ${ }^{38,39}$ The first was a double-masked randomized study in which ketorolac $0.4 \%$ was administered 3 days, 1 day, or 1 hour preoperatively and continued for 3 weeks postoperatively. ${ }^{38}$ The control group received a vehicle placebo 1 hour before surgery and for 3 weeks after surgery. All patients with a corrected distance visual acuity worse than 20/30 at 2 weeks had retinal OCT. No patients in the 3-day or 1-day ketorolac group had CME. One patient in the 1-hour ketorolac group and 3 patients in the placebo group had CME at 2 weeks. This was somewhat compelling but not statistically significant, perhaps due to the small sample size.

The second randomized prospective study of 189 patients consisted of 1 group starting topical indomethacin $0.1 \%$ three days preoperatively and continuing for 1 month postoperatively, 1 group starting indomethacin postoperatively only, and the control group receiving no indomethacin. ${ }^{39}$ Fluorescein angiography of all patients at 3 months showed no $\mathrm{CME}$ in the group treated with indomethacin preoperatively and the presence of CME in $15 \%$ of patients in the indomethacin postoperatively only group $(P=.001)$ and $33 \%$ in the control group $(P<.001)$. Visual acuity at 3 months was also better in the pretreatment group than in the other 2 groups $(P=.005)$.

Both studies were limited by a small sample size and the use of topical steroid by all participants. However, they suggest that preoperative use of topical NSAIDs might be beneficial in preventing CME. 


\section{Postoperative Use for Prevention of Cystoid Macular Edema}

The evaluation of NSAIDs for the prevention of CME includes older NSAIDs as well as newer NSAID medications. Diclofenac has been around the longest. Miyake et al. ${ }^{40,41}$ found that diclofenac was more effective in preventing CME than a topical corticosteroid eyedrop, fluorometholone. Asano et al. ${ }^{42}$ also found a reduction in angiographic $\mathrm{CME}$ when comparing topical diclofenac and betamethasone. Newer NSAIDs that have been evaluated in this manner include nepafenac. Miyake et al. ${ }^{43}$ found that nepafenac $0.1 \%$ was more effective in preventing CME following cataract surgery than fluorometholone $0.1 \%$. Another newer NSAID is bromfenac $0.1 \%$. Miyanaga et al. ${ }^{44}$ reported that bromfenac $0.1 \%$ was effective in decreasing ocular inflammation following cataract surgery. Wang et al. ${ }^{45}$ showed that bromfenac $0.1 \%$ was superior to both fluorometholone and dexamethasone in preventing CME following phacoemulsification.

Some older topical NSAIDs are officially approved for the maintenance of mydriasis during cataract surgery and for controlling postoperative pain. The use of these medications for CME prevention is therefore considered off-label. The newer NSAIDS have been reformulated to increase their potency and to allow less frequent dosing postoperatively and have also been approved by evaluating their effect on anterior segment inflammation as gauged by cell and flare as well as postoperative pain.

Kessel et al. ${ }^{26}$ reviewed the literature regarding the efficacy of topical steroids and topical NSAIDs in reducing postoperative inflammation and preventing CME. They identified 7 randomized clinical trials that compared the prevalence of CME following cataract surgery with the use of topical steroids or NSAIDs. One study comprised patients with diabetes and was excluded from the authors' analysis. A review of the other 6 studies in a meta-analysis of the incidence of CME found that 4 evaluated the presence of CME by fluorescein angiogram 5 weeks after surgery and the remaining 2 evaluated the presence of CME using retinal OCT evaluation 1 month after cataract surgery. When the patients receiving steroids were compared with those receiving NSAIDs, the metaanalysis found that the incidence of CME was higher at 1 month in the steroid-only patients (25.3\%) versus the NSAID-only patients $(3.8 \%)$. Further analysis of the studies showed that so-called potent and weaker steroids were less effective than NSAIDs in preventing CME. ${ }^{26}$

An even more recent systematic review and meta-analysis of the prevention of CME after cataract surgery in nondiabetic and diabetic patients has been reported by Wielders et al. ${ }^{46}$ They described 17 trials that reported incidence rates and found that topical NSAIDs significantly reduced the odds of developing CME compared with topical corticosteroids in nondiabetic and mixed populations. A combination of topical corticosteroids and NSAIDs notably reduced the odds of developing CME compared with topical corticosteroids alone in nondiabetic and diabetic patients.

The question of whether a combination of an NSAID and a steroid is more effective than a steroid alone was evaluated in a recent study by Zaczek et al. ${ }^{47}$ The study found that a combination of nepafenac plus dexamethasone reduced subclinical macular swelling and inflammation compared with dexamethasone alone. However, the low rate of CME in this study made it difficult to find a significant difference when looking at frank CME. The 
authors used an increase in macular thickness evaluated with OCT as a surrogate marker for the development of CME. Wittpenn et al. ${ }^{48}$ found that adding perioperative ketorolac to postoperative prednisolone reduced the incidence of CME and macular thickening in cataract surgery patients already at low risk for CME.

Another recent study that retrospectively reviewed more than 16000 phacoemulsification surgeries by 17 surgeons defined clinical postoperative macular edema as a visual acuity of 20/40 or worse with confirmatory findings on OCT. ${ }^{49}$ Compared with eyes that received prophylaxis with topical prednisolone alone, the eyes that were additionally treated with postoperative NSAIDs experienced a $55 \%$ reduction in the incidence of macular edema.

Another important question is whether the combination of NSAIDs and corticosteroid is more effective than the use of NSAIDs alone. In their metaanalysis, Wielders et al. ${ }^{46}$ concluded that although a combination of NSAIDs and corticosteroids significantly reduced the chances of developing CME compared with topical corticosteroids alone, the combination did not show any benefit over topical NSAIDs in an indirect treatment comparison. They suggested that a topical NSAID should always be part of the preventive treatment after surgery in nondiabetic patients, but whether the use of corticosteroid eyedrops can be avoided cannot be concluded from the results.

The duration of postoperative treatment using an NSAID for the prevention of CME is not clear as there are no good randomized studies evaluating this issue; however, there is a trend toward prolonged use of NSAIDs for 4 to 6 weeks postoperatively following uneventful cataract surgery to prevent CME. The use of NSAIDs can be prolonged for up to 12 weeks in potentially high-risk patients. ${ }^{50}$

\section{Postoperative Use for Treatment of Cystoid Macular Edema}

As important as the prevention of CME is the treatment of CME if it develops after cataract surgery. Cystoid macular edema can be subclinical and relatively self-limiting, with little effect on visual acuity. Studies looking at the prevalence of CME have reported that when fluorescein angiography is used to make the diagnosis, the prevalence is much higher than when loss of visual acuity is used to make the diagnosis. Thus, many milder subclinical episodes of CME are unrecognized and resolved without treatment. However, it is important that patients with clinically significant CME be treated before the edema can damage the macula. ${ }^{51}$

The use of NSAIDs to treat CME has a long history, with reviews of the treatment of aphakic or pseudophakic CME dating back to the 1980s. ${ }^{52}$ Although the use of topical NSAIDs is critical in the treatment of CME, there is some evidence that combination therapy of a topical NSAID and a corticosteroid may act synergistically and be superior to either medication used alone. ${ }^{53} \mathrm{~A}$ small randomized controlled study compared topical ketorolac and topical prednisolone with combination therapy for the treatment of pseudophakic CME. ${ }^{54}$ The authors found that the combination of the 2 medications led to improvement in Snellen visual acuity over 3 months. Patients treated with either combination therapy or ketorolac alone responded more quickly than patients in the corticosteroid group. This early study is indicative of a possible synergistic effect of 
combining NSAIDs and corticosteroids. However, it is difficult to assess the efficacy of steroids in CME as many of the results are confounded by concomitant use of NSAIDs in many of the studies reported. ${ }^{55}$

There are no recent reports of the use of oral NSAIDS in the treatment of postoperative CME. However, in their 1979 study of the use of oral indomethacin pretreatment on aphakic $\mathrm{CME},{ }^{56}$ Klein et al. reported a decrease in the incidence of aphakic CME compared with the incidence in a control group. There has also been 1 report of an intravitreal NSAID used for the treatment of CME of various etiologies. Soheilian et al. ${ }^{57}$ reported the use of intravitreal diclofenac $500 \mathrm{mg} / 0.1 \mathrm{~mL}$ in 1 eye with pseudophakic CME. While no toxic effects were noted, there was no significant improvement in the central macular thickness.

Chronic CME can be difficult to treat and often requires the use of NSAIDs in combination with corticosteroids or other treatments including antiangiogenesis drugs. Warren et al. ${ }^{58}$ evaluated various combination therapies including different topical NSAIDs or placebo combined with intravitreal steroids and antiangiogenesis treatments. They concluded that the NSAID therapy helped the improvement produced by the steroids and antivascular endothelial growth factor therapy. The NSAIDs also showed a benefit in reducing retinal thickness compared with a placebo in this study.

\section{Special Considerations for Glaucoma Patients having Cataract Surgery Perioperative Use of Prostaglandin Analogs and the Need for Nonsteroidal Antiinflammatory Drugs}

Prostaglandin analogues (PGAs) are the most commonly prescribed ophthalmic medication. Many patients having cataract surgery are on a topical PGA for the treatment of glaucoma and/or ocular hypertension. Several case reports and 1 case series have shown an association between PGA use and postoperative CME after uneventful cataract surgery, which is consistent with the mechanism of PGAs in their role of increasing vascular permeability. In the series by Yeh and Ramanathan, ${ }^{59}$ NSAIDs were not used after surgery and CME developed in eyes receiving latanoprost only. The CME resolved in all cases after latanoprost was discontinued and ketorolac was initiated.

In an open-label trial, Miyake et al. ${ }^{60}$ compared glaucomatous eyes after cataract surgery; 1 group was treated with latanoprost and fluorometholone and 1 group with latanoprost and diclofenac. At 5 weeks, angiographic CME was seen in 30 of 37 eyes in the PGA-steroid group and 3 of 35 eyes in the PGA-NSAID group. No difference in visual acuity was found. The authors concluded that latanoprost disrupts the blood-aqueous barrier (BAB) and increases the incidence of angiographic CME after cataract surgery and that these effects can be prevented when an NSAID is given concurrently. ${ }^{60}$

In clinical practice, many ophthalmologists discontinue PGA around the time of cataract surgery despite the lack of evidence that this influences visual outcomes. Fortunately, cataract surgery alone may result in IOP reduction, decreasing the need for topical therapy. In addition, other agents such as a fixed dorzolamide-timolol combination are more effective than PGAs in lowering IOP immediately after surgery. ${ }^{61}$ Prostaglandin analogues can be 
added later as needed for IOP control in combination with an NSAID if used in the first few weeks after surgery and on their own if added later. A study of 41 eyes by Moghimi et al. ${ }^{62}$ found that latanoprost started at least 4 months after uneventful cataract surgery did not cause angiographic CME or a change in macular thickness.

Although the evidence for or against using PGAs in the cataract perioperative period is limited, a general statement can be made that when PGA use is required in the early postoperative period, the concomitant use of an NSAID may reduce the risk for angiographic CME.

\section{Effectiveness of Nonsteroidal Antiinflammatory Drugs in Preventing Pseudophakic Cystoid Macular Edema in the Glaucoma Patient}

The effectiveness of NSAIDs in preventing CME after standalone cataract surgery in glaucoma patients has not been extensively studied. The occurrence of clinically significant CME after extracapsular cataract surgery in glaucoma patients has been reported to be high (11.6\%), although no comparable comparison group was studied ${ }^{63}$ However, it is unclear whether this finding is related to the use of specific glaucoma medications available in the mid-1980s when this report was published. A subsequent retrospective review by Law et al. ${ }^{64}$ did not find a notable difference in the incidence of clinical CME after standalone cataract surgery between glaucoma patients (700 [5.14\%]) and nonglaucoma patients (553 [5.79\%]). This study also found that glaucoma medications used preoperatively or postoperatively were not associated with clinical CME $(P>.05)$. The lack of prospective multicenter studies with an appropriate control group and a clear definition for macular edema limits any concrete comparisons of the incidence of CME between glaucoma patients and nonglaucoma patients having cataract extraction.

\section{Nonsteroidal Antiinflammatory Drugs with Combined Cataract and Glaucoma Procedures}

The role and value of NSAIDs in the perioperative management of cataract surgery in combination with glaucoma surgery are incompletely characterized in the medical literature. A single small study ${ }^{65}$ compared diclofenac and dexamethasone following combined cataract and trabeculectomy procedures, reporting higher and broader blebs and a trend toward lower IOP in the NSAID group than in the steroid group. Given the paucity of data to guide the use of NSAIDs following cataract surgery combined with trabeculectomy, tube shunt implantation, or minimally invasive glaucoma procedures, NSAID use should be based on the nature of surgery planned, individual patient characteristics, and the anticipated risks and benefits of their use.

\section{Nonsteroidal Antiinflammatory Drug Use in Cataract Patients with Pseudoexfoliation Syndrome}

To our knowledge, there are no published studies of the role of NSAIDs in eyes with pseudoexfoliation (PXF) syndrome having cataract surgery. Despite this, the use of NSAIDs in some of these patients may be warranted. Pseudoexfoliation syndrome is the most common identifiable cause of open-angle glaucoma. ${ }^{66}$ Although cataract extraction will have a long-term beneficial effect in lowering IOP in patients with PXF syndrome, ${ }^{67-69}$ the eyes of these patients may have significant IOP elevation in the immediate postoperative 
period. ${ }^{70}$ Many of the patients may be on multiple topical glaucoma medications, and some may require continuation or addition of PGAs to control their IOP. As stated previously, the concomitant use of NSAIDs with PGAs may reduce the incidence of anterior chamber flare and angiographic CME in these patients.

Cataract surgery has been demonstrated to have a notably higher incidence of surgical complications in patients with PXF syndrome than in those without this condition. The complications stem from risks such as small pupils, shallow anterior chambers, posterior vitreous pressure, vitreous prolapse, zonular dialysis, and capsule fragility. ${ }^{71}$ Many of the risks and the underlying pathology of PXF syndrome with an altered BAB can lead to significant postoperative inflammation in the early postoperative period. ${ }^{72,73}$ Eyes with an altered $\mathrm{BAB}$ would be expected to have a greater incidence of CME. ${ }^{74}$ In addition, iris trauma, which is more likely to occur in eyes with PXF syndrome, is an additional risk factor for the development of CME ${ }^{75}$ Considering all the potential risk factors for CME, the use of preoperative and postoperative NSAIDs in individuals with PXF syndrome should be considered..$^{71}$

\section{Treatment Paradigms}

\section{Monotherapy for Postoperative Inflammation}

Although a combination of topical NSAIDs and steroids appears to be more effective than either agent alone in the treatment of CME, a more interesting question is how NSAIDs alone compare with steroids in the treatment of inflammation following cataract surgery. Monotherapy with NSAIDs may be extremely useful in patients at risk for adverse events from topical steroids. This includes steroid responders, brittle diabetics (sensitive to systemic absorption), and individuals with recurrent herpetic keratitis and delayed wound healing. A recent study comparing the effectiveness of topical bromfenac and prednisolone acetate found that the NSAID was as effective as the topical steroid in controlling postoperative inflammation in routine cataract surgery. ${ }^{76}$ The potential for monotherapy with NSAIDs offers a simplified effective postoperative regimen without the possible adverse effects of topical steroids. ${ }^{77}$

\section{Universal Versus Selective Nonsteroidal Antiinflammatory Drugs}

There are 2 basic approaches to the use of NSAIDs in patients having cataract surgery. The universal approach uses NSAIDs in combination with steroids in all patients, whereas the selective method reserves NSAIDs for high-risk cases only. High-risk cases include patients more likely to develop macular edema following surgery such as individuals with diabetes, ${ }^{78}$ uveitis, ${ }^{79}$ radiation retinopathy, vascular occlusions, ${ }^{27}$ epiretinal membranes, ${ }^{27}$ or retinitis pigmentosa ${ }^{80}$ or individuals who developed CME in their fellow eye. The selective approach would also be reserved for routine patients who developed CME following surgery or had excessive iris manipulation during surgery. The selective method is designed to prevent potential NSAID adverse side effects in eyes at low risk for the development of CME and also to lower the financial burden of expensive topical NSAIDs. Both universal and selective approaches to incorporating NSAIDs have validity, and neither should be considered a standard of care in modern cataract surgery. 


\section{Adverse Effects of Topical Nonsteroidal Antiinflammatory Drugs}

Systemic absorption of most topical NSAIDs is minimal. Consequently, topical administration is seldom associated with the same side effects as oral administration. Nevertheless, documented NSAID allergies, cross-reactions, and intolerances require consideration and discussion with the patient if topical equivalents are to be used. There are many reports of NSAIDs worsening asthma, but almost all were in preexisting asthmatics. $^{81-83}$

Burning, stinging, conjunctival injection, and contact dermatitis are the most commonly reported adverse side effects of NSAIDs. ${ }^{84,85}$ Most topical NSAIDs are weakly acidic to improve corneal penetration. As such, they are naturally more irritating than more neutral topical medications.

Nonsteroidal antiinflammatory drugs have been reported to cause superficial punctate keratitis, ${ }^{86}$ subepithelial infiltrates and immune rings, ${ }^{87}$ stromal infiltrates, ${ }^{88}$ and epithelial defects. ${ }^{89}$ In 1999, the American Society of Cataract and Refractive Surgery received several reports of corneal stromal ulcers in patients using topical NSAIDs. In response, a generic form of diclofenac (Falcon Pharmaceuticals) was withdrawn from the market even though several of the published early cases also implicated nongeneric Voltaren. ${ }^{21}$ Shortly thereafter, a retrospective review of several cases suggested that coexistent ocular morbidity was more to blame than simple drug toxicity. ${ }^{90}$ However, after withdrawal of the Falcon product, reports to the U.S. Food and Drug Administration (FDA) of severe corneal events associated with NSAID use markedly declined. ${ }^{91}$ One group suggested the inactive ingredients of the generic product (which were different from those of Voltaren) as possible etiologic factors. ${ }^{92}$ Recently, a comparative effectiveness retrospective study of over 4500 eyes that received generic diclofenac, flurbiprofen, or ketorolac revealed no corneal melts or other significant corneal events other than 1 instance of temporary mild corneal thinning in an eye treated with prednisolone alone in a patient with rheumatoid arthritis. ${ }^{49}$

Every topical NSAID has been implicated in severe corneal events. ${ }^{90,93-100}$ The common denominator in almost all cases was a preexisting epithelial defect. ${ }^{101}$ Topical NSAIDs may be an additional trigger following cataract surgery that turns an epithelial defect into a melt in eyes that are at risk for ulceration. ${ }^{97}$ The role of NSAIDs in wound healing is still to be elucidated. Of particular concern is diclofenac blockage of lipoxygenase enzymes since this can indirectly inhibit the keratocyte proliferation that is necessary for wound healing. ${ }^{102}$

Due to the potential local side effects of topical NSAIDs, certain ocular and systemic conditions warrant extra consideration and additional monitoring. These conditions include corneal denervation, corneal epithelial defects (especially traumatic, diabetic, neurotrophic, and contact lens related), rheumatoid arthritis, rosacea, keratitis sicca, complex or repeat ophthalmic surgeries, and concomitant use of other medications that inhibit healing or are toxic to the epithelium. ${ }^{91}$ Frequent or prolonged dosing, even in low-risk eyes, requires a careful history, examination, and monitoring. ${ }^{91,101,103}$ Continued misuse of topical NSAIDs may contribute to continued adverse events. ${ }^{21}$ 
The most worrisome side effects of topical steroids in cataract surgery would be steroidinduced glaucoma first, followed by delayed wound healing, ocular rebound inflammation, and opportunistic infections including fungi and herpes simplex virus.

\section{Conclusion}

Since the approval of flurbiprofen by the FDA in 1988, ophthalmic NSAIDs have enjoyed an almost 30-year history of significant safety and demonstrable effectiveness. Any medication can place patients at risk for side effects. However, given the extraordinary number of annual doses of topical NSAIDs, the frequency of adverse events appears to be exceptionally low and acceptable.

Topical NSAIDs have been useful in preventing intraoperative miosis, postoperative inflammation, and the development of CME. In addition, they may modulate postoperative pain and inhibit the proliferation of LECs that are responsible for PCO. Nonsteroidal antiinflammatory drugs have a synergistic effect with steroids on the development of CME but may be used alone in high-risk eyes in which topical steroid use may be detrimental.

Whether used solely in eyes at increased risk for the development of CME or universally in all patients having cataract surgery, the benefits of these topical medications should be assessed by each clinician as appropriate for their particular practice or patient population. This is especially true for many glaucoma patients who may be using PGAs at the time of cataract surgery or who may be prone to CME due to complicated surgery from PXF syndrome. A thorough understanding of the potency, approaches for avoiding and treating CME, and adverse reactions and contraindications of these medications should help surgeons maximize their benefits and improve surgical outcomes and patient satisfaction.

\section{References}

1. Ahuja M, Dhake AS, Sharma SK, Majumdar DK. Topical ocular delivery of NSAIDs. AAPS J. 2008; 10:229-241. [Accessed April 27. 2016] Available at: http://www.ncbi.nlm.nih.gov/pmc/ articles/PMC2751374/pdf/12248_2008_Article_9024.pdf. [PubMed: 18437583]

2. Colin J. The role of NSAIDs in the management of postoperative ophthalmic inflammation. Drugs. 2007; 67:1291-1308. [PubMed: 17547472]

3. Flach AJ. Topical nonsteroidal anti-inflammatory drugs in ophthalmology. Int Ophthalmol Clin. 2002; 42:1-11.

4. Schalnus R. Topical nonsteroidal anti-inflammatory therapy in ophthalmology. Ophthalmologica. 2003; 217:89-98. [PubMed: 12592044]

5. Rojanasakul Y, Robinson JR. Transport mechanisms of the cornea: characterization of barrier permselectivity. Int J Pharm. 1989; 55:237-246.

6. Gupta M, Majumdar DK. Effect of concentration, $\mathrm{pH}$ and preservatives on in vitro transcorneal permeation of ibuprofen and flurbiprofen from non-buffered aqueous drops. Indian J Exp Biol. 1997; 35:844-849. [PubMed: 9475059]

7. Ahuja M, Dhake AS, Majumdar DK. Effect of formulation factors on in vitro permeation of diclofenac from experimental and marketed aqueous eye drops through excised goat cornea. Yakugaku Zasshi. 2006; 126:1369-1375. [Accessed April 27, 2016] Available at: https:// www.jstage.jst.go.jp/article/yakushi/126/12/126_12_1369/_pdf. [PubMed: 17139162]

8. Walsh DA, Moran HW, Shamblee DA, Uwaydah IM, Welstead WJ Jr, Sancilio LF, Dannenburg WN. Anti-inflammatory agents. 3. Synthesis and pharmacological evaluation of 2-amino-3benzoylphenylacetic acid and analogues. J Med Chem. 1984; 27:1379-1388. [PubMed: 6436487] 
9. Stewart RH, Grillone LR, Shiffman ML, Donnenfeld ED, Gow JA. The systemic safety of bromfenac ophthalmic solution 0.09\%. J Ocul Pharmacol Ther. 2007; 23:601-612. [PubMed: 18001250]

10. Yanni, JM., Graff, G., Hellberg, MR., inventors; Alcon Laboratories, Inc., assignee. Topically administrable compositions containing 3-benzoylphenylacetic acid derivatives for treatment of ophthalmic inflammatory disorders. US Patent 5475 034. Dec 12. 1995 Available at: http:// patft.uspto.gov/netacgi/nph-Parser?Sect1ZPTO1\&Sect2ZHITOFF\&dZPALL\&pZ1\&uZ \%2Fnetahtml\%2FPTO\%2Fsrchnum.htm\&rZ1\&fZG\&1Z50\&s1Z5475034.PN.\&OSZPN/ 5475034\&RSZPN/5475034

11. Waterbury LD, Silliman D, Jolas T. Comparison of cyclooxygenase inhibitory activity and ocular anti-inflammatory effects of ketorolac tromethamine and bromfenac sodium. Curr Med Res Opin. 2006; 22:1133-1140. [PubMed: 16846546]

12. Ogawa T, Sakaue T, Terai T, Fukiage C. Effects of bromfenac sodium, non-steroidal antiinflammatory drug, on acute ocular inflammation [Japanese]. Nippon Ganka Gakkai Zasshi. 1995; 99:406-411. [PubMed: 7741052]

13. Van der Bijl P, van Eyk AD, Seifart HI, Viljoen I, Jooste M. Transmucosal permeation of topically applied diclofenac and piroxicam. J Appl Res. 2003; 3:505-511. [Accessed April 27, 2016] Available at: http://jrnlappliedresearch.com/articles/Vol3Iss4/vanderBijl.pdf.

14. Ahuja M, Sharma SK, Majumdar DK. In vitro corneal permeation of diclofenac from oil drops. Yakugaku Zasshi. 2007; 127:1739-1745. [Accessed April 27, 2016] Available at: https:// www.jstage.jst.go.jp/article/yakushi/127/10/127_10_1739/_pdf. [PubMed: 17917432]

15. Masuda, K., Ikari, T., Matsuyama, T., Terashima, A., Goto, T., inventors; Kakenyaku Kako Co. Ltd., assignee. [Accessed April 27, 2016] Anti-inflammatory ophthalmic solution and process for preparing the same. US patent 4474 811. Oct 2. 1984 Available at: http://patft.uspto.gov/netacgi/ nph-Parser?Sect1ZPTO1\&Sect2ZHITOFF\&dZPALL\&Z1\&uZ\%2Fnetahtm1\%2FPTO \%2Fsrchnum.htm\&rZ1\&fZG\&1Z50\&s1Z4474811.PN.\&OSZPN/4474811\&RSZPN/4474811

16. Malhotra M, Majumdar DK. In vitro transcorneal permeation of ketorolac tromethamine from buffered and non-buffered aqueous ocular drops. Indian J Exp Biol. 1997; 35:941-947. [PubMed: 9475074]

17. Kennah HE II, Hignet S, Laux PE, Dorko JD, Barrow CS. An objective procedure for quantitating eye irritation based upon changes of corneal thickness. Fundam Appl Toxicol. 1989; 12:258-268. [PubMed: 2714526]

18. Gamache DA, Graff G, Brady MT, Spellman JM, Yanni JM. Nepafenac, a unique nonsteroidal prodrug with potential utility in the treatment of trauma-induced ocular inflammation: I. Assessment of anti-inflammatory efficacy. Inflammation. 2000; 24:357-370. [PubMed: 10850857]

19. Ke TL, Graff G, Spellman JM, Yanni JM. Nepafenac, a unique nonsteroidal prodrug with potential utility in the treatment of trauma-induced ocular inflammation: II. In vitro bioactivation and permeation of external ocular barriers. Inflammation. 2000; 24:371-384. [PubMed: 10850858]

20. Kapin MA, Yanni JM, Brady MT, McDonough TJ, Flanagan JG, Rawji MH, Dahlin DC, Sanders $\mathrm{ME}$, Gamache DA. Inflammation-mediated retinal edema in the rabbit is inhibited by topical nepafenac. Inflammation. 2003; 27:281-291. [PubMed: 14635785]

21. Kim SJ, Flach AJ, Jampol LM. Nonsteroidal anti-inflammatory drugs in ophthalmology. Surv Ophthalmol. 2010; 55:108-133. [PubMed: 20159228]

22. Cho H, Wolf KJ, Wolf EJ. Management of ocular inflammation and pain following cataract surgery: focus on bromfenac ophthalmic solution. Clin Ophthalmol. 2009; 3:199-210. [Accessed April 27, 2016] Available at: http://www.ncbi.nlm.nih.gov/pmc/articles/PMC2709021/pdf/ opth-3-199.pdf. [PubMed: 19668566]

23. Radi, ZA., Ostroski, R. [Accessed April 27, 2016] Pulmonary and cardiorenal cyclooxygenase-1 (COX-1), -2 (COX-2), and microsomal prostaglandin E synthase-1 (mPGES-1) and -2 (mPGES-2) expression in a hypertension model; Mediators Inflamm. 2007. p. 85091Available at: http:// www.ncbi.nlm.nih.gov/pmc/articles/PMC1906712/pdf/MI2007-85091.pdf

24. Mishima S, Tanishima T, Masuda K. Pathophysiology and pharmacology of intraocular surgery. Aust N Z J Ophthalmol. 1985; 13:147-158. [PubMed: 3902061] 
25. Hashemi H, Seyedian MA, Mohammadpour M. Small pupil and cataract surgery. Curr Opin Ophthalmol. 2015; 26:3-9. [PubMed: 25390859]

26. Kessel L, Tendal B, Jørgensen KJ, Erngaard D, Flesner P, Lundgaard Andresen J, Hjortdal J. Postcataract prevention of inflammation and macula edema by steroid and nonsteroidal antiinflammatory eye drops; a systematic review. Ophthalmology. 2014; 121:1915-1924. [Accessed April 27, 2016] Available at: http://www.aaojournal.org/article/S0161-6420(14)00389-3/pdf. [PubMed: 24935281]

27. Henderson BA, Kim JY, Ament CS, Ferrufino-Ponce ZK, Grabowska A, Cremers SL. Clinical pseudophakic cystoid macular edema; risk factors for development and duration after treatment. $\mathrm{J}$ Cataract Refract Surg. 2007; 33:1550-1558. [PubMed: 17720069]

28. Nishi K, Nishi O. Tissue culture of human lens epithelial cells. Part II: Suppressive effect of diclofenac sodium on their proliferation and metaplasia [Japanese]. Nippon Ganka Gakki Zasshi. 1991; 95:581-590.

29. Powe NR, Schein OD, Gieser SC, Tielsch JM, Luthra R, Javitt J, Steinberg EP. for the Cataract Patient Outcome Research Team. Synthesis of the literature on visual acuity and complications following cataract extraction with intraocular lens implantation. Arch Ophthalmol. 1994; 112:239252. erratum, 889. [PubMed: 8037792]

30. Schein OD, Steinberg EP, Javitt JC, Cassard SD, Tielsch JM, Steinwachs DM, Legro MW, DienerWest M, Sommer A. Variation in cataract surgery practice and clinical outcomes. Ophthalmology. 1994; 101:1142-1152. [PubMed: 8008356]

31. Lum F, Schein O, Schachat AP, Abbott RL, Hoskins HD Jr, Steinberg EP. Initial two years of experience with the AAO National Eyecare Outcomes Network (NEON) cataract surgery database. Ophthalmology. 2000; 107:691-697. [PubMed: 10768330]

32. Zaidi FH, Corbett MC, Burton BJL, Bloom PA. Raising the benchmark for the 21 st century-the 1000 cataract operations audit and survey: outcomes, consultant-supervised training and sourcing NHS choice. Br J Ophthalmol. 2007; 91:731-736. [Both accessed April 27, 2016] Available at: http://www.ncbi.nlm.nih.gov/pmc/articles/PMC1955623/pdf/731.pdf Correction to Table 2 available at: http://bjo.bmj.com/content/suppl/2007/05/30/bjo. 2006.104216.DC1/916731webonlyfig.pdf. [PubMed: 17050577]

33. Jaycock P, Johnston RL, Taylor H, Adams M, Tole DM, Galloway P, Canning C, Sparrow JM. the UK EPR User Group. The Cataract National Dataset electronic multicentre audit of 55567 operations: updating benchmark standards of care in the United Kingdom and internationally. Eye. 2009; 23:38-49. [Accessed April 27, 2016] Available at: http://www.nature.com/eye/ journal/v23/n1/pdf/6703015a.pdf. [PubMed: 18034196]

34. Greenberg PB, Tseng VL, Wu WC, Liu J, Jiang L, Chen CK, Scott IU, Friedmann PD. Prevalence and predictors of ocular complications associated with cataract surgery in United States veterans. Ophthalmology. 2011; 118:507-514. [PubMed: 21035868]

35. Clark A, Morlet N, Ng JQ, Preen DB, Semmens JB. Whole population trends in complications of cataract surgery over 22 years in Western Australia. Ophthalmology. 2011; 118:1055-1061. [PubMed: 21310493]

36. Packer M, Lowe J, Fine H. Incidence of acute postoperative cystoid macular edema in clinical practice. J Cataract Refract Surg. 2012; 38:2108-2111. [PubMed: 23084360]

37. Chaudhary C, Bahadhur H, Gupta N. Study of cystoid macular edema by optical coherent tomography following uneventful cataract surgery. Int Ophthalmol. 2015; 35:685-691. Available at: http://download.springer.com/static/pdf/36/art\%253A10.1007\%252Fs10792-014-9998-5.pdf? originUrlZhttp\%3A\%2F\%2Flink.springer.com\%2Farticle \%2F10.1007\%2Fs10792-014-9998-5\&token2ZexpZ1461784156waclZ\%2Fstatic\%2Fpdf \%2F36\%2Fart\%25253A10.1007\%25252Fs10792-014-9998-5.pdf\%3ForiginUr1\%3Dhttp\%253A $\% 252 \mathrm{~F} \% 252$ Flink.springer.com\%252Farticle \%252F10.1007\%252Fs10792-014-9998-5*whmacZd89ba24720ab9187786fd12fe0716450af38ce0 c69e0b2bd6ee80394d9958af1. [PubMed: 25205061]

38. Donnenfeld ED, Perry HD, Wittpenn JR, Solomon R, Nattis A, Chou T. Preoperative ketorolac tromethamine $0.4 \%$ in phacoemulsification outcomes: Pharmacokinetic-response curve. J Cataract Refract Surg. 2006; 32:1474-1482. [PubMed: 16931258] 
39. Yavas GF, Öztürk F, Küsbeci T. Preoperative topical indomethacin to prevent pseudophakic cystoid macular edema. J Cataract Refract Surg. 2007; 33:804-807. [PubMed: 17466852]

40. Miyake K, Masuda K, Shirato S, Oshika T, Eguchi K, Hoshi H, Majima Y, Kimura W, Hayashi F. Comparison of diclofenac and fluorometholone in preventing cystoid macular edema after small incision cataract surgery: a multicentered prospective trial. Jpn J Ophthalmol. 2000; 44:58-67. [PubMed: 10698027]

41. Miyake K, Nishimura K, Harino S, Ota I, Asano S, Kondo N, Miyake S. The effect of topical diclofenac on choroidal blood flow in early postoperative pseudophakias with regard to cystoid macular edema formation. Invest Ophthalmol Vis Sci. 2007; 48:5647-5652. [Accessed April 12, 2016] Available at: http://iovs.arvojournals.org/article.aspx?articleidZ2125278. [PubMed: 18055815]

42. Asano S, Miyake K, Ota I, Sugita G, Kimura W, Sakka Y, Yabe N. Reducing angiographic cystoid macular edema and blood-aqueous barrier disruption after small-incision phacoemulsification and foldable intraocular lens implantation; multi-center prospective randomized comparison of topical diclofenac $0.1 \%$ and betamethasone 0.1\%. J Cataract Refract Surg. 2008; 34:57-63. [PubMed: 18165082]

43. Miyake K, Ota I, Miyake G, Numaga J. Nepafenac $0.1 \%$ verus fluorometholone $0.1 \%$ for preventing cystoid macular edema after cataract surgery. J Cataract Refract Surg. 2011; 37:15811588. [PubMed: 21855758]

44. Miyanaga M, Miyai T, Nejima R, Maruyama Y, Miyata K, Kato S. Effect of bromfenac ophthalmic solution on ocular inflammation following cataract surgery. Acta Ophthalmol. 2009; 87:300-305. [Accessed April 26, 2016] Available at: http://onlinelibrary.wiley.com/doi/10.1111/j. 1755-3768.2008.01433.x/pdf. [PubMed: 19183412]

45. Wang, Qw, Yao, K., Xu, W., Chen, Pq, Shentu, Xc, Xie, X., Weng, Y., Zhang, L., Jin, Cf, Wu, W., Zhu, Yn, Yu, Yh. Bromfenac sodium 0.1\%, fluorometholone $0.1 \%$ and dexamethasone $0.1 \%$ for control of ocular inflammation and prevention of cystoid macular edema after phacoemulsification. Ophthalmologica. 2013; 229:187-194. [PubMed: 23429038]

46. Wielders LHP, Lambermont VA, Schouten JSAG, van den Biggelaar FJHM, Worthy G, Simons RWP, Winkens B, Nuits RMMA. Prevention of cystoid macular edema after cataract surgery in nondiabetic and diabetic patients: A systematic review and meta-analysis. Am J Ophthalmol. 2015; 160:968-981. [PubMed: 26232601]

47. Zaczek A, Artzen D, Laurell CG, Stenevi U, Montan P. Nepafenac 0.1\% plus dexamethasone 0.1\% versus dexamethasone alone: effect on macular swelling after cataract surgery. J Cataract Refract Surg. 2014; 40:1498-1505. [PubMed: 25135542]

48. Wittpenn JR, Silverstein S, Heier J, Kenyon KR, Hunkeler JD, Earl M, on behalf of the Acular LS for Cystoid Macular Edema (ACME) Study Group. A randomized, masked comparison of topical ketorolac $0.4 \%$ plus steroid vs steroid alone in low-risk cataract surgery patients. Am J Ophthalmol. 2008; 146:554-560. [PubMed: 18599019]

49. Shorstein NH, Liu L, Waxman MD, Herrinton LJ. Comparative effectiveness of three prophylactic strategies to prevent clinical macular edema following phacoemulsification surgery. Ophthalmology. 2015; 122:2450-2460. [PubMed: 26409728]

50. O'Brien TP. Emerging guidelines for the use of NSAID therapy to optimize cataract surgery patient care. Curr Med Res Opin. 2005; 21:1131-1137. erratum, 1431-1432. [PubMed: 16004683]

51. Hunter AA, Modjtahedi SP, Long K, Zawadzki R, Chin EK, Caspar JJ, Morse LS, Telander DG. Improving visual outcomes by preserving outer retina morphology in eyes with resolved pseudophakic cystoids macular edema. J Cataract Refract Surg. 2014; 40:626-631. [PubMed: 24529660]

52. Jampol LM. Pharmacologic therapy of aphakic and pseudophakic cystoid macular edema; 1985 Update. Ophthalmology. 1985; 92:807-810. [PubMed: 3897936]

53. Flach AJ. The incidents, pathogenesis, and treatment of cystoid macular edema following cataract surgery. Trans Am Ophthalmol Soc. 1998; 96:557-634. [Accessed April 27, 2016] Available at: http://www.pubmedcentral.nih.gov/picrender.fcgi?artidZ1298410\&blobtype=pdf. [PubMed: 10360304] 
54. Heier JS, Topping TM, Baumann W, Dirks MS, Chern S. Ketorolac versus prednisolone versus combination therapy in the treatment of acute pseudophakic cystoid macular edema. Ophthalmology. 2000; 107:2034-2038. discussion by AJ Flach, 2039. [PubMed: 11054327]

55. Shelsta HN, Jampol LM. Pharmacologic therapy of pseudophakic cystoid macular edema; 2010 update. Retina. 2011; 31:4-12. [PubMed: 21187730]

56. Klein RM, Katzin HM, Yannuzzi LA. The effect of indomethacin pretreatment on aphakic cystoids macular edema. Am J Ophthalmol. 1979; 87:487-489. [PubMed: 443312]

57. Soheilian M, Karimi S, Ramezni A, Teyman GA. Pilot study of intravitreal injection of diclofenac for treatment of macular edema of various etiologies. Retina. 2010; 30:509-515. [PubMed: 19952986]

58. Warren KA, Bahrani H, Fox JE. NSAIDs in combination therapy for the treatment of chronic pseudophakic cystoid macular edema. Retina. 2010; 30:260-266. [PubMed: 20175270]

59. Yeh PC, Ramanathan S. Latanoprost and clinically significant cystoid macular edema after uneventful phacoemulsification with intraocular lens implantation. J Cataract Refract Surg. 2002; 28:1814-1818. [PubMed: 12388034]

60. Miyake K, Ota I, Maekubo K, Ichihashi S, Miyake S. Latanoprost accelerates disruption of the blood-aqueous barrier and the incidence of angiographic cystoid macular edema in early postoperative pseudophakias. Arch Ophthalmol. 1999; 117:34-40. [Accessed April 27, 2016] Available at: http://archopht.jamanetwork.com/article.aspx?articleidZ411378. [PubMed: 9930158]

61. Rainer G, Menapace R, Findl O, Petternel V, Kiss B, Georgopoulos M. Intraindividual comparison of the effects of a fixed dorzolamidetimolol combination and latanoprost on intraocular pressure after small incision cataract surgery. J Cataract Refract Surg. 2001; 27:706-710. [PubMed: 11377900]

62. Moghimi S, Zandian M, Latifi G, Amini H, Eslami Y, Zarei R, Fakhraie G, Nouri-Mahdavi K. Topical latanoprost does not cause macular thickening after uncomplicated cataract surgery. J Ophthalmic Vis Res. 2012; 7:289-294. [Accessed April 27, 2016] Available at: http:// www.ncbi.nlm.nih.gov/pmc/articles/PMC3595585/pdf/JOVR-07-289.pdf. [PubMed: 23503128]

63. Handa J, Henry JC, Krupin T, Keates E. Extracapsular cataract extraction with posterior chamber lens implantation in patients with glaucoma. Arch Ophthalmol. 1987; 105:765-769. [PubMed: 3579706]

64. Law SK, Kim E, Yu F, Caprioli J. Clinical cystoid macular edema after cataract surgery in glaucoma patients. J Glaucoma. 2010; 19:100-104. [PubMed: 20160577]

65. Levkovitch-Verbin H, Katz G, Kalev-Landoi M, Goldenfeld M. Postoperative treatment with topical diclofenac versus topical dexamethasone after combined phacotrabeculectomy with mitomycin C. J Glaucoma. 2013; 22:177-182. [PubMed: 22027932]

66. Ritch R. Exfoliation syndromedthe most common identifiable cause of open-angle glaucoma. $\mathrm{J}$ Glaucoma. 1994; 3:176-178. [PubMed: 19920577]

67. Shingleton BJ, Heltzer J, O'Donoghue MW. Outcomes of phacoemulsification in patients with and without pseudoexfoliation syndrome. J Cataract Refract Surg. 2003; 29:1080-1086. [PubMed: 12842671]

68. Dosso AA, Bonvin ER, Leuenberger PM. Exfoliation syndrome and phacoemulsification. J Cataract Refract Surg. 1997; 23:122-125. [PubMed: 9100119]

69. Pohjalainen T, Vesti E, Uusitalo RJ, Laatikainen L. Intraocular pressure after phacoemulsification and intraocular lens implantation in non-glaucomatous eyes with and without pseudoexfoliation. $\mathrm{J}$ Cataract Refract Surg. 2001; 27:426-431. [PubMed: 11255056]

70. Levkovitch-Verbin H, Habot-Wilner Z, Burla N, Melamed S, Goldenfeld M, Bar-Sela SM, Sachs D. Intraocular pressure elevation within the first 24 hours after cataract surgery in patients with glaucoma or exfoliation syndrome. Ophthalmology. 2008; 115:104-108. [PubMed: 17561259]

71. Shingleton BJ, Crandall AS, Ahmed K II. Pseudoexfoliation and the cataract surgeon: preoperative, intraoperative, and postoperative issues related to intraocular pressure, cataract, and intraocular lenses. J Cataract Refract Surg. 2009; 35:1101-1120. [PubMed: 19465298]

72. Schumacher S, Nguyen NX, Küuchle M, Naumann GOH. Quantification of acqueous flare after phacoemulsification with intraocular lens implantation in eyes with pseudoexfoliation syndrome. 
Arch Ophthalmol. 1999; 117:733-735. [Accessed April 27, 2016] Available at: http:// archopht.jamanetwork.com/article.aspx?articleidZ411976. [PubMed: 10369582]

73. Shastri L, Vasavada A. Phacoemulsification in Indian eyes with pseudoexfoliation syndrome. J Cataract Refract Surg. 2001; 27:1629-1637. [PubMed: 11687363]

74. Ursell PG, Spalton DJ, Whitcup SM, Nussenblatt RB. Cystoid macular edema after phacoemulsification: relationship to blood-aqueous barrier damage and visual acuity. J Cataract Refract Surg. 1999; 25:1492-1497. [PubMed: 10569164]

75. Gulkilik G, Kocabora S, Taskapili M, Engin G. Cystoid macular edema after phacoemulsification: risk factors and effect on visual acuity. Can J Ophthalmol. 2006; 41:699-703. [PubMed: 17224950]

76. Walter KA, Estes AI, Watson S, Ellingboe M. Management of ocular inflammation following routine cataract surgerydtopical corticosteroid (prednisolone) versus topical non-steroidal (bromfenac). US Ophthalmic Rev. 2011; 4:97-100. [Accessed April 27, 2016] Available at: http:// www.touchophthalmology.com/sites/www.touchophthalmology.com/files/ellingboe_0.pdf.

77. Findl O. Redefining the treatment paradigm for post-operative inflammation control -the role of topical non-steroidal anti-inflammatory drugs. Eur Ophthalmic Rev. 2010; 4:54-59. [Accessed April 27, 2016] Available at: http://www.touchophthalmology.com/sites/ www.touchophthalmology.com/files/findl.pdf.

78. Schmier JK, Halpern MT, Covert DW, Matthews GP. Evaluation of costs for cystoid macular edema among patients after cataract surgery. Retina. 2007; 27:621-628. [PubMed: 17558326]

79. Bélair ML, Kim SJ, Thorne JE, Dunn JP, Kedhar SR, Brown DM, Jabs DA. Incidence of cystoid macular edema after cataract surgery in patients with and without uveitis using optical coherence tomography. Am J Ophthalmol. 2009; 148:128-135. [PubMed: 19403110]

80. Park S, Lim LT, Gavin MP. Topical steroids and nonsteroidal antiinflammatory drugs for the treatment of cystoid macular edema in retinitis pigmentosa. Retin Cases Brief Rep. 2013; 7:134 136. [PubMed: 25390804]

81. Sharir M. Exacerbation of asthma by topical diclofenac [letter]. Arch Ophthalmol. 1997; 115:294295. [PubMed: 9046277]

82. Sheehan GJ, Kutzner MR, Chin WD. Acute asthma attack due to ophthalmic indomethacin. Ann Intern Med. 1989; 111:337-338. [PubMed: 2757315]

83. Sitenga GL, Ing EB, Van Dellen RG, Younge BR, Leavitt JA. Asthma caused by topical application of ketorolac. Ophthalmology. 1996; 103:890-892. [PubMed: 8643243]

84. Flach AJ. Cyclo-oxygenase inibitors in ophthalmology. Surv Ophthalmol. 1992; 36:259-284. [PubMed: 1549810]

85. Gaynes BI, Fiscella R. Topical nonsteroidal anti-inflammatory drugs for ophthalmic use; a safety review. Drug Saf. 2002; 25:233-250. [PubMed: 11994027]

86. Gills JP. Voltaren associated with mediation keratitis [letter]. J Cataract Refract Surg. 1994; 20:110. [PubMed: 8133470]

87. Probst LE, Machat JJ. Corneal subepithelial infiltrates following photorefractive keratectomy [letter]. J Cataract Refract Surg. 1996; 22:281.

88. Sher NA, Krueger RR, Teal P, Jans RG, Edmison D. Role of topical corticosteroids and nonsteroidal antiinflammatory drugs in the etiology of stromal infiltrates after excimer photorefractive keratectomy [letter]. J Refract Corneal Surg. 1994; 10:587-588. [PubMed: 7530111]

89. Shimazaki J, Saito H, Yang HY, Toda I, Fujishima H, Tsubota K. Persistent epithelial defect following penetrating keratoplasty: an adverse effect of diclofenac eyedrops. Cornea. 1995; 14:623-627. [PubMed: 8575187]

90. Flach AJ. Corneal melts associated with topically applied nonsteroidal anti-inflammatory drugs. Trans Am Ophthalmol Soc. 2001; 99:205-210. [Accessed April 27, 2016] discussion, 210-212; Available at: http://www.ncbi.nlm.nih.gov/pmc/articles/PMC1359011/pdf/11797308.pdf. [PubMed: 11797308]

91. Gaynes BI, Onyekwuluje A. Topical ophthalmic NSAIDs: a discussion with focus on nepafenac ophthalmic suspension. Clin Ophthalmol. 2008; 2:355-368. [Accessed April 27, 2016] Available 
at: http://www.ncbi.nlm.nih.gov/pmc/articles/PMC2693998/pdf/co-2-355.pdf. [PubMed: 19668727]

92. Hargrave SL, Jung JC, Fini E, Gelender H, Cather C, Guidera A, Udell I, Fisher S, Jester JV, Bowman RW, McCulley JP, Cavanagh HD. Possible role of the vitamin E solubilizer in topical diclofenac on matrix metalloproteinase expression in corneal melting; an analysis of postoperative keratolysis. Ophthalmology. 2002; 109:343-350. [PubMed: 11825822]

93. Asai T, Nakagami T, Mochizuki M, Hata N, Tsuchiya T, Hotta Y. Three cases of corneal melting after instillation of a new nonsteroidal anti-inflammatory drug. Cornea. 2006; 25:224-227. [PubMed: 16371788]

94. Bekendam PD, Narváez J, Agarwal M. Case of corneal melting associated with the use of topical nepafenac. Cornea. 2007; 26:1002-1003. [PubMed: 17721306]

95. Congdon NG, Schein OD, von Kulajta P, Lubomski LH, Gilbert D, Katz J. Corneal complications associated with topical ophthalmic use of nonsteroidal antiinflammatory drugs. J Cataract Refract Surg. 2001; 27:622-631. [PubMed: 11311634]

96. Di Pascuale MA, Whitson JT, Mootha VV. Corneal melting after use of nepafenac in a patient with chronic cystoid macular edema after cataract surgery. Eye Contact Lens. 2008; 34:129-130. [PubMed: 18327052]

97. Guidera AC, Luchs JI, Udell IJ. Keratitis, ulceration, and perforation associated with topical nonsteroidal anti-inflammatory drugs. Ophthalmology. 2001; 108:936-944. [PubMed: 11320025]

98. Isawi H, Dhaliwal DK. Corneal melting and perforation in Stevens Johnson syndrome following topical bromfenac use. J Cataract Refract Surg. 2007; 33:1644-1646. [PubMed: 17720085]

99. Lin JC, Rapuano CJ, Laibson PR, Eagle RC Jr, Cohen EJ. Corneal melting associated with use of topical nonsteroidal anti-inflammatory drugs after ocular surgery. Arch Ophthalmol. 2000; 118:1129-1132. [PubMed: 10922213]

100. Wolf EJ, Kleiman LZ, Schrier A. Nepafenac-associated corneal melt. J Cataract Refract Surg. 2007; 33:1974-1975. [PubMed: 17964407]

101. Abelson MB, Lilyestrom L. Melting away the myths of NSAIDs. Rev Ophthalmol. 1996; 14:124128. [Accessed April 27, 2016] Available at: http://www.reviewofophthalmology.com/content/d/ therapeutic_topics/i/1287/c/24798/.

102. Ku EC, Lee W, Kothari HV, Scholer DW. Effect of diclofenac sodium on the arachidonic cascade. Am J Med. 1986; 80(issue 4, suppl 2):18-23.

103. [Accessed April 27, 2016] Drug Class Review: Ophthalmic Nonsteroidal Anti-Inflammatory Drugs (NSAIDs). VHA Pharmacy Benefits Management Services and the Medical Advisory Panel. Jul 2009. Available at: http://www.pbm.va.gov/clinicalguidance/drugclassreviews/ OphthalmicNonsteroidalAntiInflammatoryDrugsNSAIDsReview.pdf 


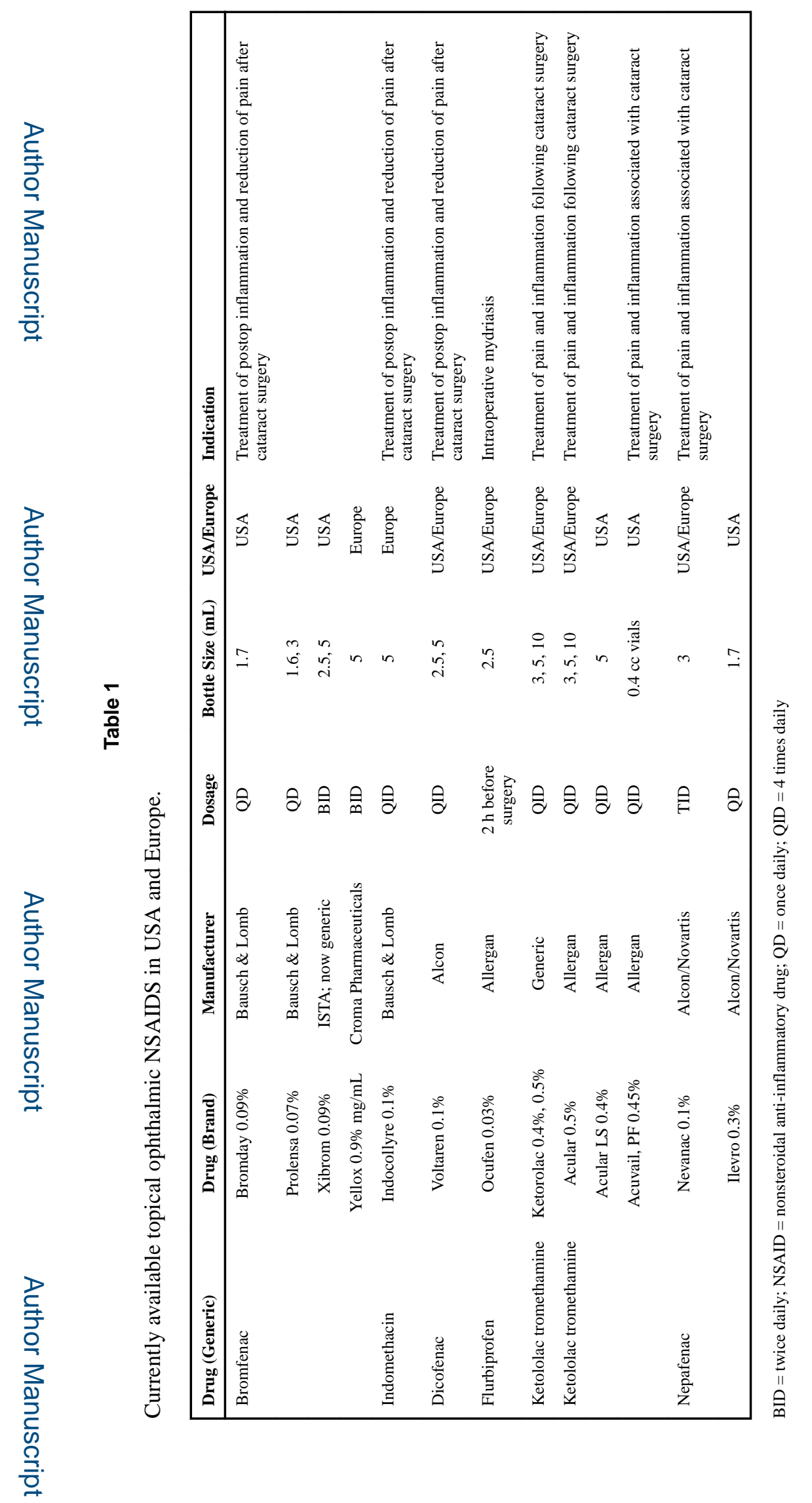

J Cataract Refract Surg. Author manuscript; available in PMC 2017 July 27. 